\title{
Causas e correções da úlcera de córnea em animais de companhia - Revisão de
}

\section{literatura}

Causes and corrections of corneal ulcer in pet animals - Literature review

Causas y correcciones de la úlcera corneal em animales de companhia - Revisión de la literatura

Recebido: 07/06/2021 | Revisado: 16/06/2021 | Aceito: 16/06/2021 | Publicado: 02/07/2021

Isadora Losekann Marcon

ORCID: https://orcid.org/0000-0003-1730-0934 Médica Veterinária, Brasil

E-mail: isadoramarcon@yahoo.com.br

Carolina da Fonseca Sapin

ORCID: https://orcid.org/0000-0002-2757-6355

Centro Universitário da Serra Gaúcha, Brasil

E-mail: carolinasapin@yahoo.com.br

\begin{abstract}
Resumo
Recentemente, a oftalmologia tem crescido progressivamente na medicina veterinária, resultando em novas descobertas das causas e dos tratamentos. A úlcera de córnea é o rompimento da membrana epitelial e o aparecimento do estroma, que é corado através da fluoresceína sódica, usado para diagnóstico da enfermidade. Tem diversos fatores condicionantes para a ocorrência. Esta revisão bibliográfica tem por objetivo reforçar aos estudantes e clínicos veterinários as causas de úlcera de córnea, a terapia mais indicada para cada caso e listar os possíveis tratamentos e defini-los. O presente estudo envolve técnicas de tratamento de úlcera de córnea. Foram utilizados artigos em bases de dados no período de 2006 a 2021, além de consultas em livros de oftalmologia veterinária. O animal com úlcera de córnea deve passar por exame clínico completo, específico e complementares, recomenda-se realizar cultura e antibiograma para adequar a terapia. Cabe ao clínico investigar os fatores que predispõe e o melhor tratamento, da mesma forma, o cirurgião deve determinar a melhor técnica conforme indicações e habilidades próprias. Novos tratamentos precisam de mais estudos sobre aplicabilidade. Mas os tratamentos cirúrgicos geralmente continuam sendo seguros e eficazes principalmente nos casos graves.
\end{abstract}

Palavras-chave: Úlcera de córnea; Terapias; Cirurgia oftálmica.

\begin{abstract}
Recently, ophthalmology has progressively grown in veterinary medicine, resulting in new discoveries of causes and treatments. Corneal Ulcer is the rupture of the epithelial membrane and the appearance of the stroma, which is stained with sodium fluorescein, used for diagnosis of the disease. It has several conditioning factors for the occurrence. This literature review aims to reinforce to students and veterinary clinicians the causes of corneal ulcers, the most suitable therapy for each case and list the possible treatments and define them. The present study involves corneal ulcer treatment techniques. Articles in databases from 2006 to 2021 were used, in addition to consultations in veterinary ophthalmology books. The animal with corneal ulcer must undergo a complete, specific and complementary clinical examination, it is recommended to perform culture and antibiogram to adjust the therapy. It is up to the clinician to investigate the predisposing factors and the best treatment, in the same way, the surgeon must determine the best technique according to his own indications and abilities. New treatments need more studies on applicability. But surgical treatments generally remain safe and effective, especially in severe cases.
\end{abstract}

Keywords: Corneal ulcer; Therapies; Ophthalmic surgery.

\section{Resumen}

Recientemente, la oftalmología ha crecido progresivamente em la medicina veterinaria, sescubriendo nuevas causas y tratamientos. La úlcera corneal es la ruptura de la membrana epitelial y la aparición del estroma, que se tiñe con fluoresceína sódica, que se utiliza para el diagnóstico de la enfermidad. Tiene vários factores condicionantes para la ocurrencia. Esta revisión de la literatura tiene como objetivo reforzar a estudiantes y clínicos veterinarios como causas de úlceras corneales, una terapia más adecuada para cada caso y uma lista de possibles métodos y defíniciones. El presente estudio incluye técnicas de tratamiento de úlceras corneales. Se utilizaron artículos en bases de datos de 2006 a 2021, además de consultas en libros de oftalmología veterinaria. El animal con úlcera corneal debe ser sometido a um examen clínico completo, específico y complementario, se recomienda realizar cultivo y antibiograma para ajustar la terapia. Depende al clínico investigar los factores predisponentes y el mejor tratamiento, de igual forma, el cirujano debe determinar la mejor técnica según sus propias indicaciones y habilidades. Los nuevos tratamientos necesitan más 
estudios sobre la aplicabilidad. Pero los tratamientos quiirúrgicos generalmente siguen siendo seguros y efectivos, especialmente en casos graves.

Palabras clave: Úlcera corneal; Terapias; Cirugía oftálmica.

\section{Introdução}

A córnea é a camada incolor e avascular da túnica fibrosa do globo ocular (Gelatt et al., 2014). Tem como função, devido sua forma elíptica, refratar e transmitir luz e sustentar o conteúdo intraocular. Ainda é responsável por manter a pressão intraocular, assim o seu formato e realizar sua proteção (Gelatt et al., 2014). Tem a maior concentração de células nervosas (nervos ciliares, que provêm do nervo trigêmeo) comparadas ao restante do corpo (Gelatt et al., 2014). A proteção da córnea é feita pela presença da membrana nictante associada com o reflexo de fechamento da pálpebra (Gelatt et al., 2014). A nutrição e limpeza da córnea dependem do humor aquoso e da lágrima. Todas essas funções conferem à córnea o estado saudável. Deste modo, qualquer desequilíbrio pode levar a úlceras de córnea (Gelatt et al., 2014).

A córnea tem quatro camadas: epitélio e membrana basal, estroma, membrana de descemet (membrana basal do endotélio) e endotélio. As camadas superficiais são ricas em receptores de dor, já nas camadas mais profundas, o estroma, tem células de compressão (Gelatt et al., 2014). Na camada epitelial há células não queratinizadas, escamosas e estratificadas (Gelatt et al., 2014). Nos cães e gatos essa camada tem uma única membrana basal (Gelatt et al., 2014). O estroma é a camada mais grossa da córnea, nele, há ceratócitos, os quais são células fixas fibrosas que formam feixes e sustentam toda a camada, simultaneamente com as fibras de colágeno, proteoglicanos e glicosaminoglicanos (GAG) (Gelatt et al., 2014). A membrana de Descemet é uniforme, elástica e muito fina, dessa forma, se rompe facilmente. Além disso, acelular e composta de fibras de colágeno (Gelatt, et al., 2014). Esta camada também tem função de proteger e manter certa tensão (Gelatt et al., 2014). O endotélio corneal é uma fina camada de células achatadas (Gelatt et al., 2014). Para compensar o olho desidratado, há o mecanismo de acréscimo da vascularização e o aumento da espessura da córnea (Gelatt et al., 2014).

Sendo assim, a úlcera de córnea é o rompimento do epitélio e a exposição do estroma (Ledbetter \& Gilger, 2014). Farghali e colaboradores (2021) a definem como um defeito do epitélio com perda do estroma ou inflamação. Os fatores predisponentes para o desenvolvimento são muitos, entre eles, trauma, infecção bacteriana ou fúngica e doenças imunomediadas (Farghali et al., 2021).

As úlceras de córnea são classificadas de acordo com sua profundidade, envolvimento e etiologia, como por exemplo, bactérias, vírus, fungos ou até por agentes químicos (Ledbetter \& Gilger, 2014). Alguns autores relacionam características faciais com o surgimento da lesão.

Os sinais clínicos característicos são lacrimejamento, blefarospasmos, fotofobia, hiperemia conjuntival, edema de córnea e miose (Ledbetter \& Gilger, 2014). Jégou se Tromeur (2014) especificam que a neovascularização da córnea, inflamação e edema acentuam a degeneração corneana. Ledbetter e Gilger (2014) ressaltam que além dos sinais clínicos para diagnóstico, deve ser utilizada fluoresceína sódica tópica a fim de corar o estroma exposto. Após o reconhecimento da úlcera de córnea pelos sinais clínicos, exame clínico geral e específico, deve-se compreender a causa primária. Este trabalho tem por objetivo revisar as técnicas de tratamento utilizadas nos casos de úlcera de córnea na oftalmologia veterinária assim como suas vantagens, pós-operatórios e recidivas.

\section{Metodologia}

O presente estudo é uma revisão bibliográfica qualitativa (Pereira et al., 2018) que envolve técnicas de tratamento de úlcera de córnea. Foram pesquisados artigos publicados no período de 2006 a 2021 nas plataformas de pesquisa SciELO, CAPES, PUBMED, MEDLINE, LUME (UFRGS) e ISFM, além de consultas em livros de oftalmologia veterinária, cirurgia e 
clínica médica de pequenos animais.

Os indexadores utilizados para a pesquisa foram em português: úlcera de córnea; veterinária; cães; gatos; animais de companhia; pequenos animais; cirurgia. Já em inglês: corneal ulcer; veterinary; dogs; cats; surgery. Após a seleção dos artigos, foram coletadas informações pertinentes à pesquisa.

\section{Resultados e Discussão}

\section{Predisposições e Causas Primárias}

Ao tratar a úlcera de córnea, o clínico deve verificar a possível causa primária, atentando-se a anormalidades oculares, como agenesia, entropia, dermoide e neoplasias (Sila \& Davidson, 2011). Hartley (2010) também ressalta anormalidades da lágrima e deficiências neurológicas (paralisia do nervo trigêmeo e do nervo facial) como possíveis causas. Já Eaton e colaboradores (2017) alertam que muitas vezes na clínica de animais de companhia, as causas não são identificáveis.

Estudos indicam que há relação entre as conformidades faciais e o surgimento da úlcera de córnea, como o tamanho da abertura das pálpebras (que deixa os olhos proeminentes), crânios braquicefálicos, presença de pregas nasais e exposição da esclera (Packer et al., 2015; Guyonnet, 2020). Packer e colaboradores (2015) em seu estudo descrevem que cães que tinham dobras no nariz eram cinco vezes mais predispostos a desenvolver úlcera de córnea, já em braquicefálicos essa chance elevouse em 20 vezes. Além disso, o aumento da largura da pálpebra e o aparecimento da esclera aumentam cerca de três vezes cada. Ainda na mesma pesquisa, a maioria dos cães acometidos eram machos de raças pequenas, sendo a mais comum o Pug (Packer et al., 2015).

Farghali e colaboradores (2021) alegam a prevalência de úlcera de córnea maior em fêmeas do que em machos e entre os cães, as raças mais acometidas eram Rottweiler, São Bernardo e Griffon. Lacerda (2016) concorda em que a maior prevalência ocorre em braquicefálicos, que corresponderam a 74\% dos casos em seu trabalho, assim como no estudo de Jaksz e colaboradores (2020), com cerca de 66,66\% dos animais braquicefálicos. Jégou e Tromeur (2014) desenvolveram pesquisa referente a ulcera de córnea em felinos e obtiveram como resultado maior incidência da doença em Persas (braquicéfalo), totalizando 12 animais (61\% dos animais). Resultado semelhante foi obtido por Farghali e colaboradores (2021).

O olho hígido normalmente resiste a infecções bacterianas, já, quando há uma solução de continuidade, pode resultar em infecção, principalmente, por bactérias residentes da conjuntiva. A bactéria adere à córnea lesada, e a invade, atingindo o estroma, onde se multiplica e libera proteases, endotoxinas e exotoxinas, deste modo, células inflamatórias chegam ao sítio (Ledbetter \& Gilger, 2014). Nesse tipo de infecção, a úlcera geralmente atinge o estroma. Devem ser feita cultura e antibiograma antes de instilar qualquer substância no olho (Ledbetter \& Gilger, 2014).

Staphylococcus spp., Streptococcus spp. e Pseudomonas aeruginosa são as bactérias mais frequentes (Sila \& Davidson, 2011; Ledbetter \& Gilger, 2014; Levitt et al., 2020). Farghali e colaboradores (2021) em sua pesquisa, encontraram Staphylococcus, como o micro-organismo mais presente nos olhos dos cães. Prado e colaboradores (2006) realizaram um estudo com 19 cães com úlceras de córnea, todos submetidos a exame clínico e oftalmológico inicial. Após a cultura das amostras, em $63,6 \%$ dos pacientes foi detectado uma única bactéria e nos outros $36,4 \%$ houve duas ou mais bactérias diferentes, nas quais Staphylococcus spp. estava presente em 45,2\% (Prado et al., 2006), assim como declararam os outros autores. Ademais 22,5\% eram Corynebacterium spp (Prado et al., 2006). Deste modo, os antibióticos mais indicados no trabalho foram Gentamicina e Ciprofloxacina, Cloranfenicol e Tobramicina (Prado et al., 2006). Já no trabalho de Barachetti e colaboradores (2020), Pseudomonas aeruginosa foi a bactéria mais comum seguido de Staphylococcus sp. e Streptococcus sp., assim, os antibióticos mais usados foram quinolonas e aminoglicosídeos. A úlcera viral é menos comum em cães, geralmente ocorre em animais que estão imunocomprometidos e podem apresentar diversos sinais clínicos e conformações, como 
pontilhada, dendrítica ou geográfica (Norsworthy, 2011; Ledbetter \& Gilger, 2014). Tende a ser superficial e sem perda do estroma, exceto quando há coinfecção com bactérias, portanto é comum a administração profilática de antibióticos, a fim de evitar a infecção secundária de bactérias (Ledbetter \& Gilger, 2014; Little, 2016). Uma causa importante de úlcera de córnea em felinos é secundária a infecção herpesvírus felino (FHV-1) e com menos importância, a Chlamydophila felis (Little, 2016). No trabalho de Farghali e colaboradores (2021), o FHV-1 foi o micro-organismo mais encontrado em felinos. Little (2016) relata que o diagnóstico dos felinos deve ser com base na resposta antimicrobiana e antiviral, pela incapacidade de definir a positividade pela presença do micro-organismo ou vacinal e atenta para a toxicidade de antivirais de uso humano. Outras causas menos comuns são trauma, infecção por bactérias ou distrofia (Jégou \& Tromeur, 2014).

Apesar de ser a infecção mais rara, o Aspergillus spp. é o fungo mais isolado em cães, causa muita inflamação, como o chamado "melting" ou ceratomalácia. Assim como as úlceras virais, essa também é mais comum em animais imunocomprometidos, relatada em animais tratados com corticosteroides por um longo período de tempo (Ledbetter \& Gilger, 2014) e animais que sofreram um trauma (Pucket et al., 2012). Pucket e colaboradores (2012), que relataram o caso de um cão Bichon Frisé com úlcera de córnea fúngica, que apresentava hiperpigmentação e, após exame clínico geral e oftálmico, foi diagnosticado com ceratite colagenolítica neutrofílica grave. O tratamento consistiu em ceratectomia lamelar (retirando a área pigmentada) e conservativa com antibiótico (Trobramicina), Atropina (1\%), lubrificante, anti-inflamatório e Voriconazol tópico, este por seis semanas, que resultou na resolução total do caso e sem recidiva (Pucket et al., 2012).

Úlceras químicas ocorrem pelo contato do olho com substâncias ácidas (ácido sulfúrico, sulfuroso, clorídrico, nítrico, acético) ou, mais grave, as substâncias básicas (hidróxido de magnésio, sódio, de fósforo, entre outras) (Ledbetter \& Gilger, 2014). Tem como sinais clínicos, edema, opacidade, perda do epitélio, dor, rompimento do estroma, uveíte anterior, ou até ceratite necrótica. A lavagem imediata e prolongada com solução salina ou água reduz os danos, até o pH normalizar, para conforto do animal pode ser necessário sedar. Inclusive, o desbridamento e fechamento com a terceira pálpebra fornece nova fonte de irrigação, além do uso de antibiótico tópico, anticolagenases, midriáticos e anti-inflamatórios (Ledbetter \& Gilger, 2014).

\section{Classificações das Úlceras de Córnea}

As proteases (enzimas proteolíticas) e colagenases são necessárias durante a cicatrização, são liberadas de maneira primária como falhas nas barreiras e defesas fisiológicas. Ainda, são responsáveis pela limpeza e retirada de células desvitalizadas. Porém, quando há um desequilíbrio entre as enzimas e o seu inibidor com o filme lacrimal, surgem patologias (Ledbetter \& Gilger, 2014; Pot et al., 2014). O excesso da enzima proteolítica liquefaz o estroma corneano, que assume um aspecto gelatinoso e, portanto, chamando de "melting", ceratomalácia ou úlceras complicadas (Ledbetter \& Gilger, 2014; Guyonnet et al., 2020). Nesta fase é necessária a terapia efetiva, com antibiótico de amplo espectro e atropina, ambos tópicos. Se não tratado pode causar perfuração e até perda do olho (Ledbetter \& Gilger, 2014; Pot et al., 2014; Jaksz et al., 2020; Guyonnet et al., 2020). Prado e colaboradores (2006) indicam como antibiótico de escolha para esses casos, Gentamicina, Tobramicina, Ciprofloxacina e Amicacina. A cirurgia é realizada quando a lesão é progressiva (Pot et al., 2014). Os casos de falha na terapia conservativa observados no trabalho de Guyonnet e colaboradores (2020) totalizaram cerca de 50\%, dessa forma, os autores enumeraram técnicas cirúrgicas que podem ser utilizadas nesses casos: enxerto conjuntival, enxerto de membrana de intestino delgado ou da vesícula urinária suína, enxerto de membrana amniótica ovina ou fazer enucleação.

O sucesso do tratamento depende das enzimas proteolíticas, à medida que elas reduzem, há melhora dos sinais clínicos (Ledbetter \& Gilger, 2014; Guyonnet et al., 2020). Contudo, a patogenia desse distúrbio não está bem esclarecida. Guyonnet e colaboradores (2020) trazem como tratamento de ceratomalácia em cães, o uso de soro equino e tobramicina, caso o animal apresente uveíte é tratado com atropina (1\%) e meloxicam sistêmico. 
Um tratamento que vem sendo relatado para ceratomalácia como terapia adjuvante, e bastante indicado na medicina humana, é o uso de colágeno [reticulação UV-A/Riboflavina (vitamina B2) de fibras de colágeno]. O efeito é resultado da fotossensibilização, que polimeriza os radicais de oxigênio, induzindo as ligações cruzadas dentro do colágeno (Pot et al., 2014). Pot e colaboradores (2014) alegam que o colágeno pode facilitar o tratamento de úlceras infectadas por microorganismos resistentes, porém são necessários mais estudos sobre a eficácia e complicações.

Em animais que apresentem sinais clínicos sugestivos de úlcera de córnea, deve-se coletar uma amostra com swab e instilar fluoresceína sódica tópica nos olhos, que irá pigmentar o estroma, que confirma a lesão. Faz-se necessário realizar cultura e antibiograma para escolha do antibiótico adequado. Além de verificar as possíveis causas primárias através do exame clínico completo e específico, deve-se verificar a normalidade de função e morfologia do olho (Ledbetter \& Gilger, 2014).

As úlceras superficiais podem ser classificadas em não complicadas, progressivas ou refratárias (Ledbetter \& Gilger, 2014). São facilmente tratadas (dentro de dois a seis dias) se a causa for cessada, mas para isso, pode ser necessário o exame oftalmológico completo, conferindo a normalidade dos cílios, funcionamento das pálpebras, lágrimas e outros distúrbios. Podem ser utilizados antibióticos tópicos, de três a quatro vezes ao dia para a prevenção de infecção secundária, e agentes midriáticos, uma a duas vezes ao dia para redução dos espasmos e conforto ocular (Ledbetter \& Gilger, 2014).

A úlcera indolente, refratária, entre outras denominações, é mais comum em cães da raça Boxer, mas também é relatada em outras raças (Ledbetter \& Gilger, 2014; Eaton et al., 2017; Levitt et al., 2020) e não foi evidenciada em felinos (Little, 2016). Acomete mais animais de meia idade (Eaton et al., 2017). É caracterizada como uma úlcera epitelial, superficial, crônica e geralmente não infectada (Levitt et al., 2020). Sua etiologia ainda é pouco elucidada, mas o epitélio com alteração de maturação torna-se fracamente fixado e, também outras estruturas estão incompletas ou com variação da composição, como a membrana basal, fibrilas de colágeno, vascularização e leucócitos (Ledbetter \& Gilger, 2014; Eaton et al., 2017). Detecta-se a úlcera indolente através da aplicação de fluoresceína sódica, a qual cora em anel que difunde abaixo do epitélio, sem perda estromal. Antibióticos profiláticos devem ser instituídos a cada seis ou 12 horas, ciclopégio (atropina) para reduzir o desconforto e colar elisabetano para não evoluir para perfuração (Ledbetter \& Gilger, 2014). Tobramicina, Ciprofloxacina e Polimixina B e Gramicidina são os antibióticos de eleição, já que no trabalho de Levitt e colaboradores (2020) foram isoladas bactérias em 18\% dos cães acometidos por úlcera indolente. Eaton e colaboradores (2017) alegam que, pela patogenia incerta, a terapia é controversa, mas especifica o uso de antibiótico, desbridamento e punção do estroma em grade ou com broca de diamante são associados a taxas de sucesso. Corticosteroides são contraindicados, visto que retardam a cicatrização e defesa, a menos que haja excesso de tecido de granulação (Ledbetter \& Gilger, 2014). O tratamento pode ser único ou com combinação de terapias. Inicialmente deve se realizar o desbridamento com $s w a b$, fazendo movimentos de centro a periferia do olho sob anestesia tópica. O desbridamento pode ser repetido em sete a 14 dias e a cura ocorre entre 14 e 23 dias, em média (Ledbetter \& Gilger, 2014). Na medicina humana, o soro heterólogo diluído vem sendo usado como terapia para úlcera indolente e ceratomalácia devido à quantidade de fatores de crescimento, vitamina A, fibronectina e outros (Eaton et al., 2017). Aplicado em cães, trouxe resultados satisfatórios e sem efeitos deletérios em adição ao tratamento convencional de úlcera indolente, mas necessita de mais análises em relação a reepitelização (Eaton et al., 2017).

Ledbetter e Gilger (2014) classificam as úlceras profundas como progressivas e não progressivas. As não progressivas podem ser curadas com tratamento conservativo (Ledbetter \& Gilger, 2014). Segundo Sila e Davidson (2011) a terapia inclui antibiótico profilático, atropina oftálmica, analgésicos e em felinos, antivirais. A indicação cirúrgica ocorre quando a úlcera atinge $50 \%$ da profundidade da córnea, em casos infecciosos, crônicos ou progressivos (Ledbetter \& Gilger, 2014). Hartley (2010) descreve as indicações cirúrgicas de correção, nos felinos, para úlceras que progridem rapidamente (ceratomalácia), quando dois terços da espessura da córnea já foi acometida ou falha de resposta na terapia conservativa. Cirurgias de emergências são indicadas nos casos de descementocele e perfuração (Hartley, 2010). 
A descementocele é uma lesão profunda que além do epitélio, o estroma é completamente destruído, expondo a membrana de Descemet. Há prolapso da íris e liberação do humor aquoso. É uma emergência cirúrgica e deve ser corrigida rapidamente. Antes da cirurgia, o seguimento posterior deve ser avaliado para conhecer o prognóstico da função ocular (Ledbetter \& Gilger, 2014). As pequenas lesões (menores de cinco milímetros) podem ser tratadas com flape conjuntival. Os materiais sintéticos podem ser usados como uma ponte para o crescimento de tecido fibroso. Outra técnica que vem sendo bastante usada é o transplante corneal homólogo, indicado para descementocele e perfuração total da córnea (Ledbetter \& Gilger, 2014).

As úlceras progressivas necessitam de terapia agressiva, visto que põe em risco todo o globo ocular e por consequência, a visão. Nas úlceras profundas e complicadas, deve ser feito cultura, antibiograma e citologia com amostras da córnea para guiar a antibioticoterapia (Ledbetter \& Gilger, 2014). O tratamento baseia-se no uso de atropina 1\%, antibiótico a cada uma a duas horas, caso haja ceratomalácia ou perda estromal. Úlceras complicadas com presença de bactérias ou profundas podem causar perfurações, dessa forma, demoram mais para cicatrizar e deixam cicatrizes que podem afetar a visão. As complicações podem levar a perda do olho. As mais relatadas são ceratite ulcerativa, endoftalmite, glaucoma, phithisis bulbi, ou combinações destas (Ledbetter \& Gilger, 2014).

\section{Terapias}

No pré-operatório deve ser realizado o exame clínico completo, específico e complementares como hemograma, bioquímico e urinálise. As cirurgias devem ser precedidas de medicações pré-anestésicas que não aumentem a pressão intraocular, como os benzodiazepínicos e os opióides. Esses procedimentos necessitam de anestesia geral. O plano deve ser adequado para que o olho não se mova (Caplan \& Yu-Spight, 2014), para isso pode ser usado Atracúrio (Jaksz et al., 2020). O preparo baseia-se na tricotomia, limpeza e retirada dos pelos cuidadosamente, utilizando gaze, adesivo ou escova, sendo contraindicada a aspiração dos mesmos (Caplan \& Yu-Spight, 2014). Jaksz e colaboradores (2020) indicam posicionar o animal em decúbito dorsal ou lateral, além de lavar os olhos com solução salina para retirar possíveis pelos inseridos no olho e antissepsia com a iodopovidona 10\% na pele (Caplan \& Yu-Spight, 2014) ou diluído 1:50 em solução salina (Jaksz et al., 2020). Durante o procedimento, é importante monitorar a frequência cardíaca e o eletrocardiograma em razão da estimulação oculocardíaca, caso ocorra o estímulo, parar até normalizar e pode ser revertido com atropina e glicopirrolato. Caso o reflexo oculomotor permaneça, pode ser administrado lidocaína (Caplan \& Yu-Spight, 2014). Recomenda-se atentar para a utilização de materiais de microcirurgia (espéculo palpebral, pinças, bisturis, fios 6-0, 9-0 ou mais finos, e tesouras), ampliação (lentes) e uma boa iluminação (Hartley, 2010; Ledbetter \& Gilger, 2014; Bayley, 2018; Jaksz et al., 2020). Hartley (2010) ainda lembra que cirurgião deve ter prática com cirurgia oftálmica.

Faz-se necessário levar em conta fatores causais como presença de entrópio, baixa produção de lágrimas e exposição da córnea, uma vez que comprometem a cicatrização (Hartley, 2010). Para o entrópio, o procedimento de escolha normalmente é Hotz-Celsus (Hartley, 2010; Jaksz et al., 2020). Já para o tratamento de cílios ectópicos e distiquíase são necessários a retirada do folículo, a distiquíase, quando numerosa, pode ser tratada por crioterapia ou eletrólise (Hartley, 2010). Abcessos estromais secundários à úlcera de córnea devem ser desbridados (uma ou mais vezes) para melhor contato da medicação com a área (Hartley, 2010).

Várias técnicas são usadas para reestabelecer a integridade da córnea, entre elas: enxertos conjuntivais, transposição corneoescleral ou córneo-conjuntival, enxerto autólogo, ceratoplastia, enxertos alogênicos fresco ou congelados, membranas amnióticas, cápsula renal equina, pericárdio bovino, matriz da vesícula urinária de suínos, córnea de suínos e submucosa intestinal (Barachetti et al., 2020). A cirurgia para correção de úlcera de córnea normalmente é realizada através de enxertos ou flaps. Os flaps conjuntivais fornecem suporte e vascularização aos defeitos corneanos, nesses casos o clínico consegue 
acompanhar a câmara anterior com o objetivo de analisar a possível progressão da úlcera ou até possível decorrência de uveíte, visto que esse tipo de flape não cobre toda a córnea. Ainda permite que o animal continue a enxergar (Ledbetter \& Gilger, 2014).

O enxerto conjuntival consiste na aplicação de uma fina camada da conjuntiva, retirada da conjuntiva bulbar ou tarsal que é transposta sobre a lesão e pode ser aplicada de quatro formas: o total (ou $360^{\circ}$ ), bipedículo (ou ponte), capuz ou pedículo conjuntival. O sítio da cirurgia deve ser preparado com desbridamento prévio com ex tremo cuidado para não causar perfuração (Ledbetter \& Gilger, 2014).

O recobrimento conjuntival é usado para úlceras profundas, descementoceles e pequenas perfurações. Geralmente são retirados poucos milímetros a mais do tamanho da úlcera da conjuntiva bulbar, que adere rapidamente a córnea. É separado um fino retalho e após incisado, a poucos milímetros do limbo, então elevado a borda, separando a conjuntiva da episclera a partir da borda livre da conjuntiva (Caplan \& Yu-Spight, 2014).

Para realizar o retalho conjuntival $360^{\circ}$ é necessária a incisão circular entre dois e três milímetros do limbo, dissecar cuidadosamente e colocá-la sobre a córnea de forma para que fique justa. O excesso de tecido pode ser retirado a fim de diminuir a cicatrização (Caplan \& Yu-Spight, 2014).

Indicado em lesões longas e lineares como após suturas ou quando há necessidade de mais suprimento vascular, o bípedículo, ou chamado ponte, é um enxerto linear, fixado em dois pontos. É incisado o limbo adjacente e paralelo $\left(180^{\circ}\right)$ a lesão linear (Ledbetter \& Gilger, 2014).

Para úlceras que ocorrem na periferia do globo ocular, é utilizado o método capuz, em que o contorno da lesão é incisado, levemente dissecado e levado a cobrir a lesão. Normalmente requer duas a quatro suturas simples interrompidas (Ledbetter \& Gilger, 2014).

O retalho de cobertura, é retirado através da dissecação do fragmento mais próximo da lesão, metade da conjuntiva, episclera, que quando bem dissecado, a conjuntiva fica sobre a lesão sem necessidade de tração. Então é finalizado com suturas isoladas com fio absorvível para posicionar (Caplan \& Yu-Spight, 2014).

O retalho de terceira pálpebra permite sustentar e proteger a córnea após um trauma. O procedimento é mais simples comparado ao retalho conjuntival (Caplan \& Yu-Spight, 2014). Devido a sua fragilidade não é indicado para úlceras profundas, perfurações ou descementoceles. A técnica é realizada através da extensão e elevação da terceira pálpebra com pinça e conduzido um fio monofilamentar, absorvível, 3-0 ou 4-0, através da pálpebra superior para a terceira pálpebra sob a cartilagem e tracionar para suturar com cânula (Caplan \& Yu-Spight, 2014).

Pedículo, ou enxerto rotacional é o mais usado, útil e versátil. A base do pedículo é colocada muito próxima à lesão. É incisada a conjuntiva perpendicular a lesão, dissecada e o tecido adjacente liberado. Após, é aplicada duas incisões paralelas para a formação do pedículo que cobrirá a lesão (Ledbetter \& Gilger, 2014). É utilizado náilon ou poliglactina 7-0 a 9-0 para sutura interrompida a qual é iniciada na parte mais distal e as subsequentes distantes em média de um milímetro. O enxerto em contato com a camada epitelial normal não adere, apenas no bordo da lesão, por isso entre quatro e oito semanas após, deve ser cortado o excesso de conjuntiva. Isso vai interromper o fornecimento de sangue e deixa uma mínima cicatriz (Ledbetter \& Gilger, 2014).

A complicação mais comum nesse tipo de cirurgia é a deiscência do enxerto, geralmente quando a ferida foi mal preparada antes da implantação, quando há piora da úlcera estendendo-se ao local da sutura ou tensão excessiva do enxerto. A sutura correta, a quantidade necessária e suficiente fina de enxerto para a aplicação da conjuntava sobre a lesão, mais a terapia medicamentosa correta, diminui a chance de complicações (Ledbetter \& Gilger, 2014). Estas podem levar a necrose das pálpebras e irritação da córnea (Caplan \& Yu-Spight, 2014).

Enxertos são películas retiradas de um local e transferidas para a lesão. Podem ser constituídas de membrana (por 
exemplo, amniótica ou outra), conjuntivais, de córnea ou sintéticas (Ledbetter \& Gilger, 2014; Jaksz et al., 2020). Enxertos lamelares autógenos são indicados no caso de descementocele, perfurações e casos com abcessos (Ledbetter \& Gilger, 2014). É retirada uma lâmina de tecido corneano e depositada sobre a úlcera desbridada e suturadas com pontos simples, seja isolado ou contínuo (Jaksz et al., 2020). Como na transposição corneoescleral tem menos reação imune, reduz a chance de rejeição. A desvantagem é que a córnea fica enfraquecida (Ledbetter \& Gilger, 2014). Os enxertos são indicados para úlceras profundas estromais, malácias ou infectadas (Hartley, 2010; Jaksz et al., 2020). O pedículo pode ser seccionado após seis ou oito semanas do procedimento cirúrgico (Hartley, 2010). As possíveis complicações cursam com ceratomalácia, deiscência ou pigmentação da córnea (Jaksz et al., 2020). Jaksz e colaboradores (2020) alertam para a necessidade, após a cirurgia, de antibiótico tópico, anti-inflamatório sistêmico, colar elizabetano e até tarsorrafia, uso de lentes de contato ou bandagens.

Em lesões mais superficiais podem ser colocadas bandagens para o conforto do animal. Para isso, primeiro, é removido o epitélio da ferida, secado com esponjas de celulose ou ar, e por fim, aplicado uma gota de cola adesiva (cianocrilato). Essa é contraindicada em casos de lesões mais profundas, pois o calor gerado pela cola pode acentuar a lesão, como em descementoceles e perfurações (Hartley, 2010; Caplan \& Yu-Spight, 2014). Hartley (2010) também cita o uso do adesivo tecidual butyl-cianocrilato em úlceras superficiais, na deiscência dos enxertos e úlceras estromais.

A transposição corneoescleral, ou córneo conjuntival é um enxerto autógeno que reduz a chance de hemorragias, danos a esse tecido e também reações imunomediadas. Este tipo de pedículo é usado para lesões centrais, profundas ou até perfurantes em que possa ser retirada parte do tecido que esteja saudável. O tecido deve exceder pelo menos um milímetro da borda da lesão (Ledbetter \& Gilger, 2014). A desvantagem desse método é a retirada de tecido saudável na transposição e, portanto, deixar a cicatriz maior. Geralmente não necessita ser aparado dias após o procedimento, mas o antibiótico e a atropina devem ser administrados (Ledbetter \& Gilger, 2014).

A cicatrização inicia logo após a pressão intraocular ser reestabelecida, com a tentativa de restituir o tamanho da camada epitelial. A membrana basal e a Descemet cicatrizam lentamente. O estroma depende da síntese de colágeno, que pode deixar a córnea opaca. Além disso, o endotélio posterior cicatriza com mais facilidade em animais jovens (Ledbetter \& Gilger, 2014).

Nos últimos anos, houve o aumento no interesse por pesquisas sobre o uso de Plasma Rico em Plaquetas (PRP) usado para a reparação de úlceras de córnea em cães e gatos. O PRP é extraído do plasma, que é retirado da centrifugação do sangue total. As plaquetas aderem na lesão, liberam citocinas e fatores de crescimento que estimulam a mitose de fibroblastos e, consequentemente, produção de colágeno (Merlini et al., 2014). O PRP tem fatores de crescimento, citocinas e integrinas (Farghali et al., 2021). É uma forma de tratamento não imunológica, econômica e pode ser aplicada logo após a coleta. O estudo de Farghali e colaboradores (2021) revelou que número de aplicações de PRP é dependente da espécie e morfologia da úlcera. A média de aplicações nos cães foi de duas injeções subconjuntivais com diferença de uma semana cada, já em felinos aplicadas três (Farghali et al., 2021).

Já no trabalho de Merlini e colaboradores (2014) foi dividido em dois grupos, um utilizou tratamento tópico com colírio de PRP (autógeno) e outro tampão com recobrimento da terceira pálpebra. O estudo mostrou que ambas as técnicas foram eficazes na cicatrização, nos sinais e inflamação. Com efeitos similares, cabendo ao oftalmologista, a melhor técnica a ser empregada em cada caso (Merlini et al., 2014).

Jégou e Tromeur (2014) fizeram um estudo retrospectivo sobre cicatrização de ceratectomia superficial em gatos com úlcera crônica e defendem que se deve criar uma condição ideal, remover a inflamação e a córnea degenerada, através da ceratectomia. Os autores utilizaram o tratamento convencional (com antibióticos, anticolagenases, antivirais, interferon e suplementação com aminoácidos) associado ao desbridamento. A ceratectomia é feita sob anestesia geral (pentobarbital ou propofol) e manutenção com oxigênio e isoflurano. (Jégou \& Tromeur, 2014). 
Barachetti e colaboradores (2020) utilizaram para o tratamento de úlceras corneanas profundas, descementocele, perfurações e melanocitomas, em cães e gatos, intestino delgado (quatro camadas) de suíno, obtendo êxito em 92,3\% dos animais. Este é um tratamento acessível, rápido, que utiliza biomaterial, mas necessita de mais estudos. As complicações mais comuns foram colagenólise parcial, pigmentação corneana e sinequia anterior, além da cicatriz exuberante (Barachetti et al., 2020).

No pós-operatório das diferentes cirurgias, devem ser usadas soluções oculares, ao invés de pomadas, pois podem causar uveíte se absorvidas na câmara anterior. A terapia consiste na aplicação de antibiótico tópico a cada uma a duas horas por dois dias e cada quatro a seis horas até a vascularização da lesão (máximo cinco dias). (Caplan \& Yu-Spight, 2014). Utiliza-se atropina para diminuir a cicloplegia e minimizar a cicatriz. Ademais é indicada a utilização de antibiótico sistêmico e o uso de colar elizabetano até a completa cicatrização (Caplan \& Yu-Spight, 2014). Ainda, as lentes podem ser usadas pelo conforto e alívio da dor (Hartley, 2010).

\section{Conclusão}

Dessa forma, conclui-se que todo animal que apresenta hiperemia, blefarospasmos, fotofobia, lacrimejamento e edema de córnea é sujeito a estar com úlcera de córnea. Como preconizado, deve ser retirado uma amostra para cultura de microorganismos e antibiograma e após, instilar a fluoresceína sódica e verificar se o estroma é corado, para concluir o diagnóstico. O clínico deve atentar para a causa e os fatores primários, dessa forma corrigir as possíveis causas, e prevenir, assim, sempre que possível selecionar reprodutores que tenham olhos moderados, focinho mais longo e ausência pregas nasais. O tratamento conservativo é realizado por antibioticoterapia tópica e agentes midriáticos. Se necessária a cirurgia, utilizar da técnica mais recomendada para cada caso e de acordo com a experiência do cirurgião. Descementoceles e perfurações são emergências cirúrgicas e devem ser tratadas efetivamente tão logo quanto diagnosticadas. Tratamentos cirúrgicos são seguros e eficazes para as úlceras progressivas e profundas. Independentemente do tipo de terapia instituída, sempre deve-se recomendar o uso de colar elizabetano. Novos tratamentos e pesquisas estão surgindo na oftalmologia veterinária, sendo promissores pela resposta e facilidade de execução.

\section{Referências}

Barachetti, L., Zanni, M., Stefanello, D. \& Rampazzo, A. (2020). Use of four-layer porcine small intestinal submucosa alone as a scaffold for the treatment of deep corneal defect in dogs and cats: preliminary results. Veterinary Record, 186 (19), e28.

Bayley, K. D., Read, R. A. \& Gates, M. C. (2018). Superficial keratectomy as a treatment for non-healing corneal ulceration associated with primary corneal endothelial degeneration. Wiley. Veterinary Ophthalmology. 22(4), 485-492.

Caplan E. R. \& Yu-Spight, A. (2014). Cirurgia do Olho. In: T. W. Fossum. Cirurgia de Pequenos Animais, (4a ed.), 818-842

Eaton, J. S., Hollingsworth, S. R., Holmberg, B. J., Brown, M. H., Smith, P, J. \& Maggs, D. J. (2017). Effects of topically applied heterologous serum on reepithelization rate of superficial chronic corneal epithelial defects in dog. JAVMA. 250(9), 1014-1022.

Farghali, H. A., AbdElKader, N. A., AbuBakr H. O., Ramadan, E. S., Khattab, M. S., Salem, N. Y. \& Emam, I. A. (2021). Corneal Ulcer in Dogs and Cats: Novel Clinical Application of Regenerative Therapy Using Subconjuntival Injection of Autologous Platelet-Rich Plasma. Frontiers in Veterinary Science. 8, 641265 .

Gelatt, K. N \& Samuelson, D. A. (2014). Veterinary Ophthalmology, Essencials of Veterinary Ophthalmology, (3a ed.), 2, 12-39.

Guyonnet, A., Desquilbet, L., Faure, J., Bourget, A., Donzel, E. \& Chahori, S. (2020). Outcome of medical therapy for keratomalacia in dogs. Journal of Small Animal Practice, (4), 253-258.

Hartley, C. (2010). Treatment of Corneal Ulcers: When is surgery indicated? Journal of Feline Medicine and Surgery. 12, 398-405.

Jaksz, M., Fischer, M. C., Romero, F. E. \& Busse, C. (2020). Autologous corneal graft for the treatment of deep corneal defects in dogs: 15 cases (2014-2017) Journal of Small Animal Practice, (2), 123-130. 
Research, Society and Development, v. 10, n. 7, e57410716911, 2021

(CC BY 4.0) | ISSN 2525-3409 | DOI: http://dx.doi.org/10.33448/rsd-v10i7.16911

Jégou, J. P. \& Tromeur, F. (2014). Superficial keratectomy for chronic corneal ulcers refractory to medical treatment in 36 cats. Veterinary Ophthalmology, (4), 335-340.

Lacerda R. P., Gimenez, M. T. P., Laguna, F., Costa, D., Ríos, J. \& Leiva, M. (2016). Corneal grafting for the treatment of full-thickness corneal defects in dogs: a review of 50 cases. Veterinary Ophthalmology, (3), 222-231.

Ledbetter, E. C. \& Gilger, B. C. (2014) Canine Cornea: Diseases and Surgery. In: Gelatt, K. N. Essencials of Veterinary Ophthalmology, (3a ed.), 11, 214236

Levitt, S., Osinchuk, S. C., Bauer, B. \& Sandmeyer, L. S. (2020). Bacterial isolates of indolent ulcers in 43 dogs. Veterinary Ophthalmology, (6), 1009-1013.

Little, S. E. (2016). O gato: medicina interna. Roca: 1332p.

Merlini, N. B., Fonzar, J. F., Perches, C. S., Sereno, M. G., Souza, V. L., Estanislau, C. A., Rodas, N. R., Ranzani, J. J. T., Maia, L., Padovani, C. R. \& Brandão, C. V. S. (2014). Uso de plasma rico em plaquetas em úlceras de córnea em cães. Arq. Bras. Med. Vet. Zootec., 66(6), 1742-1750.

Packer, R. M. A., Hendricks, A. \& Burn, C. C. (2015). Impact of Facial Conformation on Canine Health: Corneal Ulceration. PLoS ONE, $10(5):$ e0123827.

Pereira, A. S., Shitsuka, D. M., Parreira, F. J. \& Shitsuka, R. (2018). Metodologia da pesquisa científica. Universidade de Santa Maria.

Pot, S. A., Gallhöfer, N. S., Matheis, F. L., Voelter-Ratson, K., Hafesi, F. \&, Spiess, B. M. (2014). Corneal collagen cross-linking as treatment for infectious and noninfectious corneal melting in cats and dog: results of a prospective, nonrandomized, controlled trial. Veterinary Ophthalmology. 17(4), 250-260.

Prado, M. R., Brito, E. H. S., Girão, M. D., Sidrim, J. J. C. \& Rocha, M. F. G. (2006). Identification and antimicrobial susceptibility of bacteria isolated from corneal ulcers of dogs. Arq. Bras. Med. Vet. Zootec. 58 (6), 1024-1029.

Pucket, J. D., Allbaugh, R. A. \& Rankin, A. J. (2012). Treatment of dematiaceous fungal keratitis in a dog. Scientific Reports, 240(9), $1104-1108$.

Sila, G. H. E. \& Davidson, H. J. (2011). Corneal Ulcer. In: Norsworthy. The Feline Patient. (4a ed.), 41, 93-95. 